\title{
Akıllı Bir Çoklu Model Arttırılmış Gerçeklik Uygulaması Ameliyat Öncesi Prosedür Becerilerinin Öğretilmesi
}

\author{
Araştırma Makalesi/Research Article
}

\author{
Zeynep TAÇGIN ${ }^{1}$, (D) Ertuğrul TAÇGIN² \\ ${ }^{1}$ Bilgisayar ve Öğretim Teknolojileri, Marmara Üniversitesi, İstanbul, Türkiye \\ ${ }^{2}$ Makina Mühendisliği, Marmara Üniversitesi, İstanbul, Türkiye \\ zeynep.tacgin@marmara.edu.tr, ertugrul.tacgin@marmara.edu.tr \\ (Geliş/Received:05.11.2019; Kabul/Accepted:23.01.2020) \\ DOI: $10.17671 /$ gazibtd. 642130
}

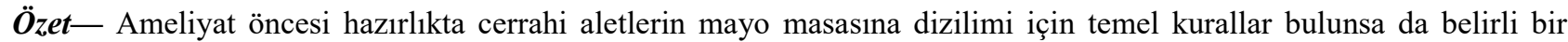
standart bulunmamaktadır. Hemşirelik öğrencileri yüksek riskli durumlar ve öğrenmeleri sırasında yetersiz geribildirim alma gibi sınılllıklar sebebiyle gereken tecrübeyi kazanmak için yeterli olanaklara sahip değildir. Bu çalışma söz konusu bu sorunun çözümü için geliştirilen akili bir çoklu model artırılmış gerçeklik uygulamasını tanıtmaktadır. Sistem uzman cerrahi hemşirelerin dizilimlerini kullanarak oluşturulan 10 doğru ve 10 hatalı dizilimle eğitilmiştir. Bu uygulamayı kullanan öğrenciler ameliyat öncesi hazinlik aşamalarını gerçekleştirdikten sonra kendi dizilimlerinin uygunluğuna ilişkin bireysel geribildirim alabilmektedir. Fiziksel ek hareketleri ile etkileşimin sağlandığı bu uygulama, Meta2 artırılmış gerçeklik gözlüğü kullanılarak geliştirilmiştir. Bu çalışma, geliştirilen çoklu model artırılmış gerçeklik uygulamasının ara yüzü, özellikleri ve akıllı sistem yapısını açıklamaktadır.
\end{abstract}

\section{A Smart Multimodal Augmented Reality Application Skill Training For Preoperative Procedures}

\begin{abstract}
Despite the current essential rules to set up the surgical instruments on the mayo table, there is no standard implementation for this stage of the preoperative preparation. The nursing students do not have enough opportunity to gain experience because of the high-risk conditions and they faced a lack of feedback during their learning. This study introduces a smart multimodal augmented reality application which developed to solve these issues. 10-correct and 10incorrect instrument arrangement of the expert nurses were used to train this system. During using this application, the learners become able to perform pre-operative operating room preparation procedures; then they can receive individual feedback about the suitability of their arrangements. Meta2 AR goggles used to provide gesture interaction. This study represents the interface, features and smart system structure of a multimodal AR.
\end{abstract}

Keywords - multimodal interface, augmented reality, nursing education, smart systems.

\author{
Abbreviations \\ MR : Mixed Reality \\ VR : Virtual Reality \\ AR : Augmented Reality \\ SDK : Software Development Kit
}

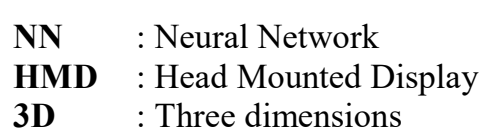

augmented virtuality. Reality continuum of Milgram sets physical and virtual reality to the edge of numerical axis and defines MR as a combination of both virtual and physical components. If the perceptions of users are

$$
\begin{array}{ll}
\text { HMD } & \text { : Head Mounted Display } \\
\text { 3D } & \text { : Three dimensions }
\end{array}
$$

Mixed reality (MR) is an umbrella term that includes
augmented reality (AR), virtual reality (VR) and

Mixed reality (MR) is an umbrella term that includes
augmented reality (AR), virtual reality (VR) and

\section{INTRODUCTION}


surrounded by entirely structured virtual components, these environments accepted as virtual. AR uses digital components to enhance the perceived physical reality as a result of an interaction. AR users can observe both the physical world and digital content together [1]. AR provides a collaborative and/or an individual learning environment depending on the features of the used display.

AR technologies have spread in several fields like entertainment, manufacture, medicine and education [2]. The hardware of AR systems has significance to amplify the functionality of software [3]. Depending on selected components, the structure of AR systems can distinguish.

AR has two main types as marker-based and markerless. Marker-based AR applications generally use fiducial markers to represent digital content. The system tracks the marker to recognise and presents the digital content onto it. Markerless AR systems use sensors to track the features of the physical environment. These systems can be locationbased or use visual search systems to enhance our reality. Marker-based AR is today's trend because of the accessibility and easy to develop structure. Everyone can develop an AR product and experience it via mobile devices. Markerless AR applications are harder to develop because of the used visual search systems, localisation or additional hardware integration.

Student-centred education uses experiential, inquiry, discovery, problem-based, situational learning techniques for providing active participation in the learning environment. However, the physical environments are not always adequate for learning because of the factors like high-risk conditions or accessibility [4-7]. The distance, time, feedback, expenses or security can be the reason to experience a situation. This is why the learners need alternative techniques for supporting their learning.

Structuring the learning environments using MR technologies might provide an effective solution to overcome these limitations [8-11]. Simulating the phenomenon and/or cases for real-life situations or abstract concepts [9] helps to gain experience. The learners not only become able to experience the learning scenarios within a low-risk learning environment and reinforce their skills via repetitive practices $[9,13]$ but also can learn the theoretical knowledge.

Past research indicated that VR could reduce the learning time and cognitive load of the students [14]. On the other hand, immersive VR might be a reason for the increased cognitive load [15]. According to Liou, Yang [16], both augmented and virtual reality systems are beneficial to support the knowledge construction of the learners [17-19]. The results of that study showed that AR was more effective than non-immersive VR for reducing cognitive load. The realistic representation of $3 \mathrm{D}$ virtual objects and discovering the environment also increase the curiosity of the learners [20]. Computer-based MR systems provide an opportunity to observe the practices [14] thus, the users become able to reflect and evaluate their learning processes [20].

\section{RELATED WORKS}

AR/VR applications are popular emerging technologies of today. According to Gardner's hype cycle, the expansion of AR is more rapid than VR [21] because of the accessibility. In addition to marker-based and markerless $\mathrm{AR}$, the interface of AR applications is classified considering the interaction techniques. There are four types of AR interfaces as tangible, collaborative, multimodal and hybrid [22].

Hybrid AR interfaces use multi-devices like wrist, HMD or robots. These devices communicate with each other to provide an output to the users [23]. Multimodal AR interfaces use natural ways to interact. Gesture control, eye tracking, facial recognition or motion recognition can be used for interaction [24]. The practitioners and researchers have started to merge these systems to produce more effective, smart and, innovative AR applications to the users.

For instance, Ismail, Billinghurst [25] developed a multimodal AR application, and they used both motion and speech recognition for interaction. Chen, Li [26] also developed a mobile AR application for dog training. They used motion and speech recognition systems to control the application. The users of this application interacted with the virtual dog and instructed it via a leap motion and a microphone.

The innovative AR systems have started to use machine learning algorithms and human-brain interfaces [27, 28]. Gang, Hui [29], Stirenko, Gordienko [30] used machine learning, visual recognition, tactile sensors and speech control for their multimodal AR interfaces that provide an opportunity for disabled users. This system is also able to present constant feedback to the users. The integrated machine learning used to interpret the neurophysical reaction data of the users. According to the researchers, this system can be integrated to use for other fields like home care, healthcare, eHealth and education. Pereira, Carter [31] developed a teleoperation robot using verbal and nonverbal behavioural interaction of a single or dual user.

Wang, Zheng [24] combined HMD and robotic technologies to manipulate the objects into the smart home. They used a computer vision image recognition system for this application. The initial interaction was provided by the scanned eye/facial expressions for measuring the physiological signals of the users. Thus, facial expressions of the users or blinking the eyes were enough to interact and control the parts of a smart home. Karambakhsh, Kamel [32] developed a learning material to teach anatomy. They used a HoloLens and gesture interaction for their application.

\subsection{Purpose}

The results of previous research [33] showed that despite completing an internship and related lectures, nursing 
students have both a lack of knowledge and skills with regard to the preoperative procedures. According to the students, they barely had an opportunity to observe the expert nurses during their internship. The crowded internship groups, sterile conditions, and time restrictions were the limitations to gain the required experience for them. According to an expert surgical nurse, they learned their professional knowledge and skills after starting the job into the operating room. Being an expert in this field took more than a year. They also confirmed that providing feedback to the internship students is not their priority because of the high-risk conditions and time restriction [33].

To represent the correct mayo table arrangement, five expert nurses from two different hospitals arranged the surgical instruments before surgery and explained the rules and procedures. They emphasised that there are principal rules for the arrangement; however, this can change doctor by doctor, operation by operation or hospital by hospital. Because of the distinguished practices of nurses, integrating a smart system algorithm to the educational AR simulation might be a solution to offer feedback to the learners. Therefore, the gathered mayo table arrangements of expert nurses were used for estimating proper arrangement and generating individual feedback to the AR users.

The purpose of this study is to develop a multimodal AR application using intuitive interaction techniques. This application is developed to reinforce the practical skills of nursing students. They can practice preoperative processes and reach individual feedback for their implementation. This paper introduces the interface, features and smart system structure of this multimodal AR application as an alternative learning tool for both nursing students and novice nurses.

\section{MATERIAL AND METHODS}

\subsection{Augmented Reality Learning Environment}

Before 3D modelling of the surgical instruments, 2D detailed pictures of each instrument were loaded to Solidworks. The realistic design for each serration and/or jaws of the instruments were essential for this learning environment. A sample 3D modelling for an instrument is shown in Figure 1.

The 3D version of the instruments was converted to fbx file format using Maya. A total of 224 surgical instruments were modelled for this application. These models were transferred to the Unity game engine for developing this application (Figure 2).

Meta2 is an AR goggle which tracks physical environment to present experience. This tethered HMD includes a depth camera to track physical components that also allows gesture recognition. The users of Meta 2 can observe both the physical environment and virtual components together and interact with the virtual components using their physical hand movements. Meta2 has its SDK for developers. After designing the environment at the Unity game engine, nine rules for preoperative procedures and the related interactions were coded using Meta2's library and $\mathrm{CH}$.

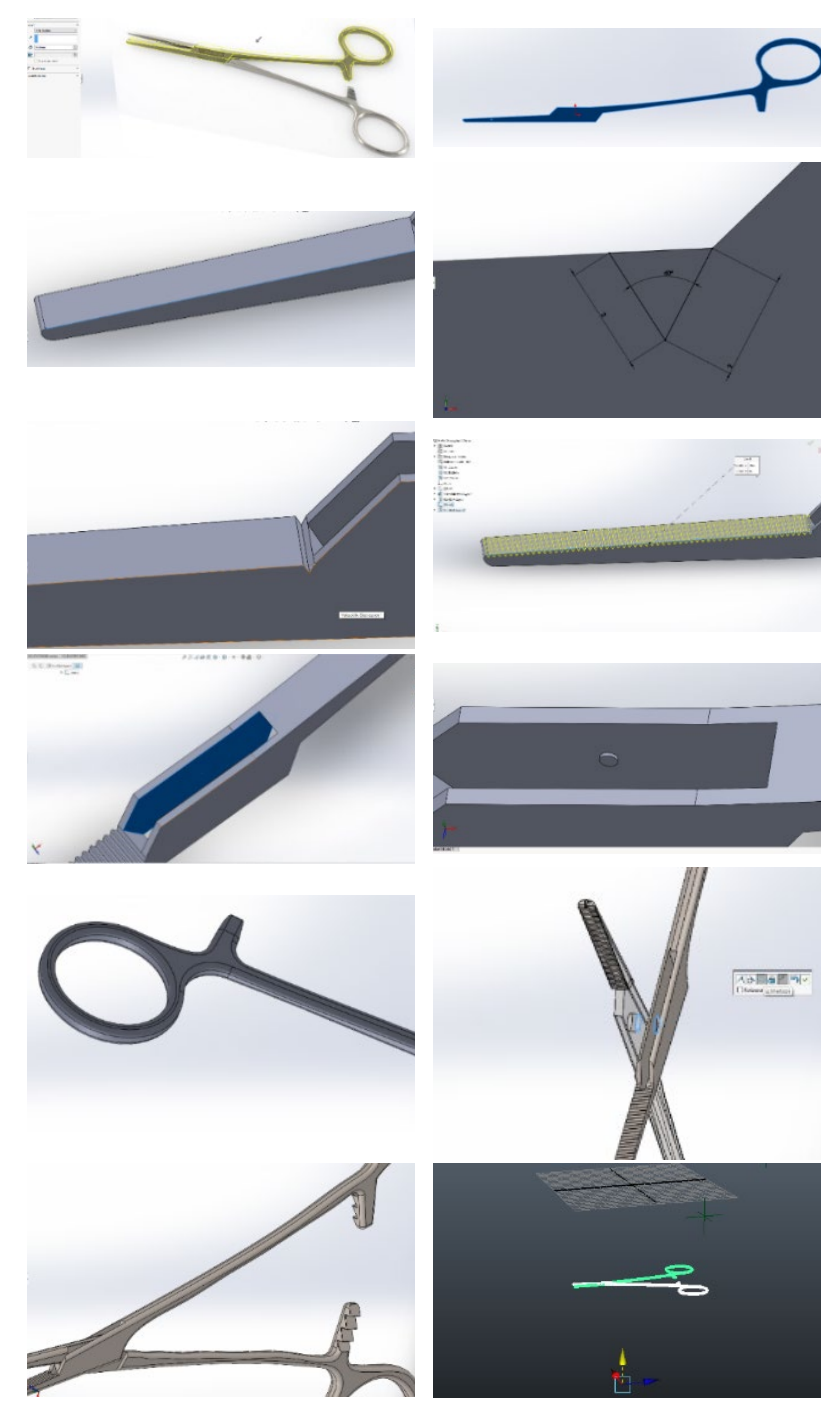

Figure 1. The sample 3D modelling process for surgical instruments

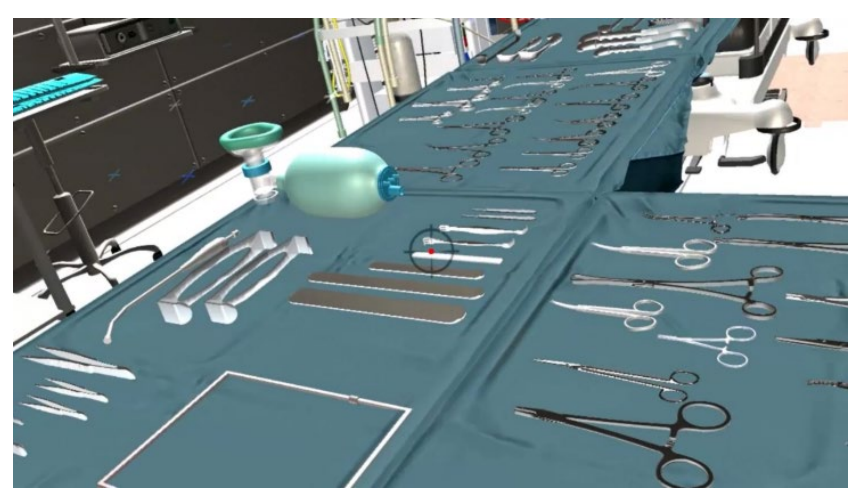

Figure 2. Representation of 3D models 


\subsection{Multimodal AR interface and interaction}

Interface

The interface of this application consists of two working tables, (1) the equipment table for presenting the sheet of mayo table and a surgical container and, (2) an empty table for arranging the surgical instruments. Besides, the users can see the sample videos concerning the procedures or choose another surgical instrument container using the panels. These two panels were added at the top of the tables and the users interacted with these panels via gaze interaction.

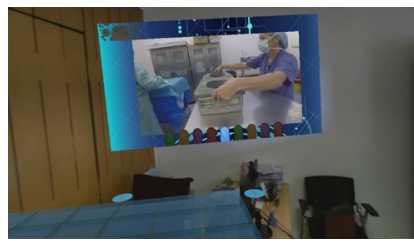

(a)

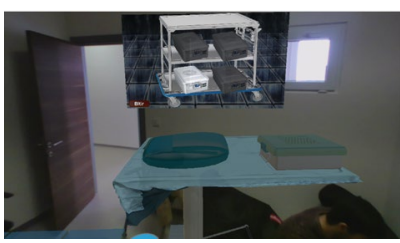

(b)

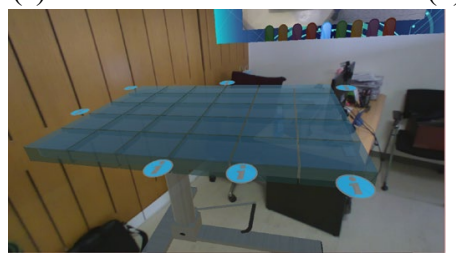

(c)

Figure 3. Interfaces

During the learning scenario, the users should pick up the sheet to spread it up to the mayo table. Then, they should unlock the caps of the surgical container, check the sterilisation indicator, pick up the surgical basket into the container sequentially. After putting the surgical basket in an empty place, they should start to set up the surgical instruments onto the mayo table.

The Mayo table is divided into 30 parts as a $5 \times 6$ matrix (Figure 3c). Each of these places is used to train the system. After evaluating the correct set up of the expert nurses, the instrument type and the areas were used to create a data matrix (Table 1). The hints were added according to the main rules and gaze interaction was used to activate tips.

As seen in Figure 3a-3b, the panels were used to offer instructional video and sample practice videos for each procedure.

\section{The interaction types}

This multimodal AR environment uses both gestures and gaze for interaction. The users can interact with the panel components via gaze interaction. They can select a video, a surgical container set or evaluate their arrangement using the button. After setting up the surgical instruments on the mayo table, the users also should count the instruments with gaze interaction as a part of the procedure. During this process, a counter appears under the right panel to present how many items did they count (Figure 4a).

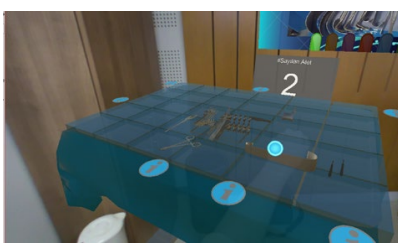

(a)

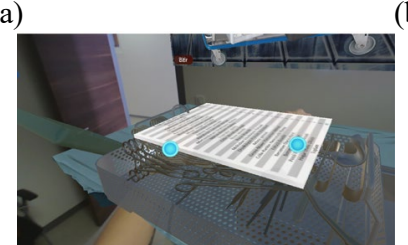

(c)

Figure 4. Interaction samples

Two types of gesture interactions are used in this application. Grabbing the items with one hand (Figure 4b) or two hands (Figure 4c). Two hands of interaction are used to carry a surgical basket and a container. One hand interaction is used for carrying the surgical instruments, an indicator filter, and the sheet.

\subsection{The explanation of the learning system}

The mayo table is divided as a $5 \times 6$ matrix to use the NN architecture. The frequency of each type of surgical instrument within a cell of this matrix is calculated to teach different correct arrangements to the system. A sample of correct arrangement for the obstetrical surgical set is offered in Table 1.

Table 1. A sample input matrix for the correct arrangement of an expert nurse

\begin{tabular}{|c|c|c|c|c|c|c|c|c|c|c|c|c|c|c|c|c|c|c|c|c|c|c|}
\hline \multicolumn{6}{|c|}{ Retractor } & \multicolumn{6}{|c|}{ Forceps } & \multicolumn{5}{|c|}{ Clamp } & \multicolumn{6}{|c|}{ Needle holder } \\
\hline 0 & 0 & 0 & 0 & 4 & 0 & 0 & \begin{tabular}{|l|l|}
0 & \\
\end{tabular} & \begin{tabular}{l|l}
0 & $(1$ \\
\end{tabular} & \begin{tabular}{l|l}
0 & $c$ \\
\end{tabular} & \begin{tabular}{l|l}
0 & \\
0
\end{tabular} & 0 & 0 & 0 & 0 & 0 & 0 & 0 & 0 & 0 & 0 & 0 & 0 \\
\hline 0 & 0 & 0 & 0 & 0 & 4 & 0 & 0 & 5 & 5 & 0 & 0 & 0 & 0 & 0 & 0 & 0 & 0 & 0 & 0 & 0 & 0 & 0 \\
\hline 0 & 0 & 0 & 0 & 0 & 0 & 0 & 0 & 5 & 5 & 0 & 0 & 0 & 0 & 0 & 0 & 0 & 0 & 0 & 0 & 0 & 0 & 0 \\
\hline 0 & 0 & 0 & 0 & 0 & 0 & 0 & 0 & 0 & 0 & 0 & 0 & 0 & 0 & 15 & 15 & 0 & 2 & 2 & 0 & 0 & 0 & 0 \\
\hline 0 & 0 & 0 & 0 & 0 & 0 & 0 & 0 & 0 & 0 & 0 & 0 & 0 & 0 & 0 & 0 & 0 & 0 & 0 & 0 & 0 & 0 & 0 \\
\hline
\end{tabular}

\begin{tabular}{|l|l|l|l|l|l|}
\hline \multicolumn{7}{|c|}{ Scalpel } \\
\hline 0 & 0 & 0 & 0 & 0 & 0 \\
\hline 0 & 0 & 0 & 0 & 0 & 0 \\
\hline 0 & 0 & 0 & 0 & 0 & 0 \\
\hline 0 & 0 & 0 & 0 & 0 & 3 \\
\hline 0 & 0 & 0 & 0 & 0 & 0 \\
\hline
\end{tabular}

\begin{tabular}{|l|l|l|l|l|l|}
\hline \multicolumn{7}{|c|}{ Scissors } \\
\hline 0 & 0 & 0 & 0 & 0 & 0 \\
\hline 0 & 0 & 0 & 0 & 0 & 0 \\
\hline 0 & 0 & 0 & 0 & 0 & 0 \\
\hline 0 & 0 & 0 & 2 & 2 & 0 \\
\hline 0 & 0 & 0 & 0 & 0 & 0 \\
\hline
\end{tabular}

\begin{tabular}{|l|l|l|l|l|l|}
\hline \multicolumn{7}{|c|}{ Frequently used } \\
\hline 0 & 0 & 0 & 0 & 0 & 0 \\
\hline 0 & 2 & 0 & 0 & 0 & 0 \\
\hline 0 & 0 & 0 & 0 & 0 & 0 \\
\hline 0 & 0 & 0 & 0 & 0 & 0 \\
\hline 0 & 0 & 0 & 0 & 0 & 0 \\
\hline
\end{tabular}

Ten correct arrangements gathered from expert surgical nurses of two different hospitals. Mayo table setup of the expert nurses was recorded by the camera during the field trip to create a data pool. In addition to the ten correct arrangements of the expert nurses, ten incorrect arrangements were defined to the system. The incorrect arrangements were created to fill the whole fields of this matrix. In other words, the cumulation of 20 sample data should not consist of a zero value for reducing to gather wrong output from this learning system algorithm. 


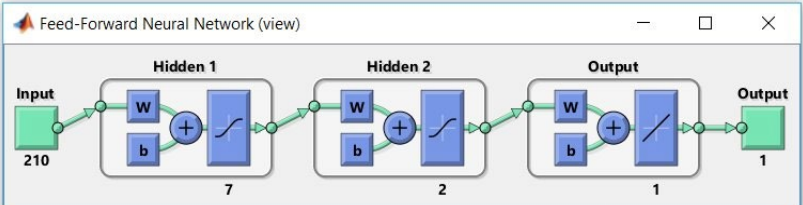

Figure 5. A forward-fed network model with 210 inputs, two layers

A total of seven surgical instrument types were assigned for the 30 different fields of a mayo table. 210 inputs were used for each assignment in this forward-fed network model. Initially, one hidden layer was used to generate an output then, an extra hidden layer was added to increase the accuracy of output. As seen in Figure 5, this system learns each sample arrangement using 210 different inputs and generates a single output. This output presents a percentage value to interpret the familiarity of the user's arrangement.

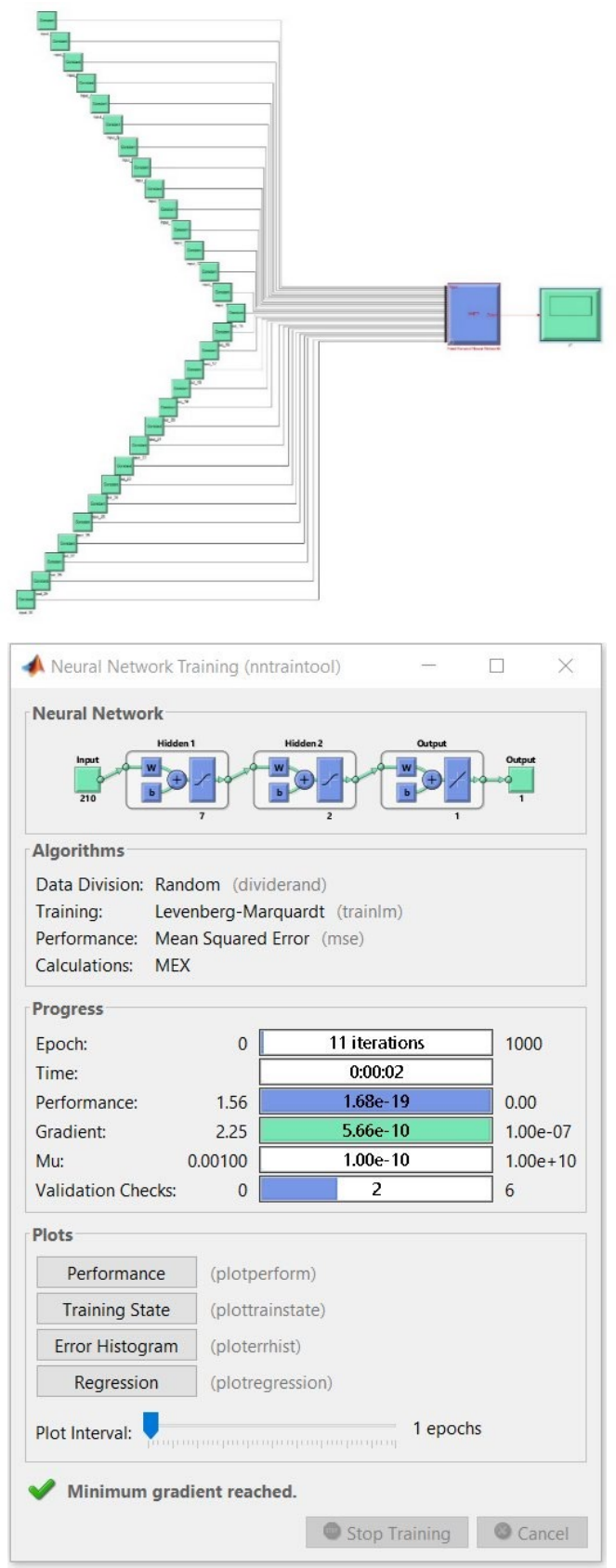

Figure 6. The interface of Simulink
This learning system structure was created using the Matlab Neural Network tool. The user inputs for each field of the mayo table were determined and assigned using the Simulink interface (Figure 6). The tangent function (blue box) was used to calculate the accuracy of inputs to offer a single output value. After defining both correct and incorrect placements, the system was able to learn, as seen in the sample training result (Figure 6). The output values were logged and defined to the Unity game engine in order to offer individual feedback to learners.

\section{DISCUSSION}

Interaction is one of the significant components of augmented and virtual reality environments. Emerging technologies provide alternative interaction types to users. Intuitive interaction techniques eliminate additional tools like controllers; therefore, experiencing mixed reality environments become more natural.

AR applications surround our lives from pocket-size mobile apps to smart houses. Enhancing the physical environment via digital components and being active in augmented reality seeks new interfaces and interaction types. Multimodal AR interfaces have derived as a result of the combination of intuitive interaction techniques and AR systems. In particular, gesture interaction became popular because of the provided active manipulation of virtual objects. Using physical hand motions enables an alternative method for skill training as well.

Spreading AR systems have the potential to be integrated almost in every area. It is anticipated that these systems will become common, and even necessary tool for reinforcing the learning processes. Researchers proved numerous instructional benefits of AR until today. Providing active participation, collaborative and individual learning, sustainable attention, motivation, facilitating memorisation, and comprehension are only some of them. It must be noted that these benefits of AR can vary according to the types of interaction and the allowed features of the interface. Tangible AR interfaces are today's trend, thanks to the easy to develop and implement structures. The visualisation of AR not only provides knowledge training but also provide skill-based training as well. Multimodal AR systems might be a powerful teaching tool for skill training because of providing intuitive interaction.

Gaining the required experience within the medical field not only takes a long time but also expects to meet a wide range of circumstances and to practise real-life conditions. Multimodal AR can be an efficient learning tool to reinforce to gain these skills. Moreover, using machine learning can be a suitable method to evaluate unstable and changeable cases for offering feedback. Trainers can find a precious opportunity to assess themselves. Thus, medical learners can develop their skills via repetitive practices and gain feedback for various cases within a low-risk learning environment. 
Using the expensive manikins is one of the most common skill training technique at the nursing faculties; however, the high expenses and an instructor dependency for feedback are disadvantages of these devices. They are adequate for a single learner under the supervising of an expert. This study offers a smart multimodal AR application as an alternative method for skill training to handle mentioned constraints.

\section{CONCLUSION AND FUTURE WORK}

A smart multimodal AR application was developed to teach the preoperative procedures and affording structured feedback to both novice nurses or nursing students. A depth camera integrated Meta2 AR HMD was used to provide gesture interaction and to facilitate the skill training of the learners. The applied technique of this multimodal AR interface has an enormous potential to develop psychomotor skills. Using machine learning algorithms can be a valuable component for enhancing feedback systems of the learning environments. Combining interaction techniques and feedback mechanisms of this study might be adapted to other fields like architecture, engineering, medical or more for reinforcing skill training processes.

The following studies should experimentally test this simulation on the target audience for evaluating the instructional effectiveness of the offered AR application. Defining more inputs to the machine learning systems can increase the reliability of an output. This system was trained using only ten correct and ten incorrect sample data because of the accessibility issue of the expert nurses. The output of this system should be evaluated after enhancing the data pool.

Learning requires not only summative feedback to measure the desired outcomes but also informative feedback leads to assist learners. The constant feedback system should ultimately be integrated into the AR applications for providing informative feedback and facilitating the learning process of the students.

\section{REFERENCES}

[1] R. Azuma, Y. Baillot, R. Behringer, S. Feiner, S. Julier, B MacIntyre, "Recent advances in augmented reality," IEEE Computer Graphics and Applications, 21(6), 34-47, 2001.

[2] K. Gül, S. Şahin, "Bilgisayar Donanım Öğretimi için Artırılmış Gerçeklik Materyalinin Geliştirilmesi ve Etkililiğinin İncelenmesi”, Bilişim Teknolojileri Dergisi, 10 (4), 353-362, 2017. DOI: $10.17671 /$ gazibtd.347604

[3] T. İçten, G. Bal, “Artırılmış Gerçeklik Teknolojisi Üzerine Yapılan Akademik Çalışmaların İçerik Analizi”, Bilişim Teknolojileri Dergisi, 10(4), 401-415, 2017. DOI: 10.17671/gazibtd.290253

[4] İ. Emre, M. Selçuk, V. Budak, M. Bütün, İ. Şimşek, "Eğitim Amaçı sanal Gerçeklik Uygulamalarında Kullanılan Cihazların Daldırma Açısından İncelenmesi”, Bilişsim Teknolojileri Dergisi, 12(2), 119-129 2019. DOI: 10.17671/gazibtd.453381
[5] J. R. Savery, T. M. Duffy, "Problem-based learning: An instructional model and its constructivist framework", Educational Technology, 25(5), 31-38, 1995.

[6] J. S. Kim, "The effects of a constructivist teaching approach on student academic achievement, self-concept, and learning strategies”, Asia Pacific Education Review, 6(1), 7-19, 2005.

[7] P. A. Kirschner, J. Sweller, R. E. Clark, "Why minimal guidance during instruction does not work: An analysis of the failure of constructivist, discovery, problem-based, experiential, and inquirybased teaching", Educational Psychologist, 41(2), 75-86, 2006.

[8] V. Ramasundaram, S. Grunwald, A. Mangeot, N. B. Comerford, C. Bliss, "Development of an environmental virtual field laboratory", Computers \& Education, 45(1), 21-34, 2005.

[9] S. Mills, J. Noyes, "Virtual reality: an overview of user-related design issues revised paper for a special issue on "Virtual reality: User Issues", Interacting with Computers, 11(4), 375-386, 1999.

[10] A. K. B. G. Bharathi, C. S. Tucker, "Investigating the impact of interactive immersive virtual reality environments in enhancing task performance in online engineering design activities." International Design Engineering Technical Conferences and Computers and Information in Engineering Conference, 2015.

[11] C. C. Jen, "Formative research on the instructional design process of virtual reality based learning environments", 2007.

[12] R. Appelman, "Designing experiential modes: A key focus for immersive learning environments", TechTrends, 49(3), 64-74, 2005.

[13] O. Osuagwu, C. Ihedigbo, C. Ndigwe, "Integrating Virtual Reality (VR) into traditional instructional design", West African Journal of Industrial and Academic Research, 15(1), 68-77, 2015.

[14] K. Hanson, B. E. Shelton, "Design and Development of Virtual Reality: Analysis of Challenges Faced by Educators", Educational Technology \& Society, 11(1), 118-131, 2008.

[15] G. Makransky, T. S. Terkildsen, R. E. Mayer, “Adding immersive virtual reality to a science lab simulation causes more presence but less learning", Learning and Instruction, 2017.

[16] H.-H. Liou, S. J. Yang, S. Y. Chen, W. Tarng, "The influences of the $2 \mathrm{D}$ image-based augmented reality and virtual reality on student learning", Journal of Educational Technology \& Society, 20(3), 110-121, 2017.

[17] S.-J. Lu, Y.-C. Liu, "Integrating augmented reality technology to enhance children's learning in marine education", Environmental Education Research, 21(4), 525-541, 2015.

[18] D. Pérez-López, M. Contero, "Delivering educational multimedia contents through an augmented reality application: A case study on its impact on knowledge acquisition and retention", Turkish Online Journal of Educational Technology-TOJET, 12(4), 19-28, 2013.

[19] N. R. Herga, B. Čagran, D. Dinevski, "Virtual laboratory in the role of dynamic visualisation for better understanding of chemistry in primary school", Eurasia Journal of Mathematics, Science \& Technology Education, 12(3), 593-608, 2016.

[20] K. M. Chuah, C. J. Chen, C.-S. Teh, "Designing a desktop virtual reality-based learning environment with emotional consideration", Research and Practice in Technology Enhanced Learning, 6(1), 25-42, 2011. 
[21] Internet: Gartner, 5 Trends Emerge in the Gartner Hype Cycle for Emerging Technologies, 2018, https://www.gartner.com/smarterwithgartner/5-trends-emerge-ingartner-hype-cycle-for-emerging-technologies-2018/, 13.03.2019.

[22] J. Carmigniani, B. Furht, M. Anisetti, P. Ceravolo, E. Damiani, M. Ivkovic, "Augmented reality technologies, systems and applications", Multimedia Tools and Applications, 51(1), 341-377, 2011.

[23] R. Altosaar, A. Tindale, J. Doyle. "Physically Colliding with Music: Full-body Interactions with an Audio-only Virtual Reality Interface", Proceedings of the Thirteenth International Conference on Tangible, Embedded, and Embodied Interaction, ACM, 2019.

[24] K.-J. Wang, C. Y. Zheng, Z.-H. Mao, "Human-Centered, Ergonomic Wearable Device with Computer Vision Augmented Intelligence for VR Multimodal Human-Smart Home Object Interaction.", 14th ACM/IEEE International Conference on Human-Robot Interaction (HRI), 767-768, 2019.

[25] A. W. Ismail, M. Billinghurst, M. S. Sunar, C. S. Yusof, "Designing an Augmented Reality Multimodal Interface for 6DOF Manipulation Techniques", Proceedings of SAI Intelligent Systems Conference, 309-322, 2018.

[26] Z. Chen, J. Li, Y. Hua, R. Shen, A. Basu, "Multimodal interaction in augmented reality", 2017 IEEE International Conference on Systems, Man, and Cybernetics (SMC), 206-209, 2017.

[27] Y. Wang, H. Zeng, A. Song, B. Xu, H. Li, L. Zhu, P. Wen, J. Liu, "Robotic arm control using hybrid brain-machine interface and augmented reality feedback", 8th International IEEE/EMBS Conference on Neural Engineering (NER), 411-414, 2017.
[28] H. Zeng, Y. Wang, C. Wu, A. Song, J. Liu, P. Ji, B. Xu, L. Zhu, H. Li, P. Wen, "Closed-loop hybrid gaze brain-machine interface based robotic arm control with augmented reality feedback", Frontiers in neurorobotics, 11(1), 60, 2017.

[29] P. Gang, J. Hui, S. Stirenko, Y. Gordienko, T. Shemsedinov, O. Alienin, Y. Kochura, N. Gordienko, A. Rojbi, J. L. Benito, "Userdriven intelligent interface on the basis of multimodal augmented reality and brain-computer interaction for people with functional disabilities", Future of Information and Communication Conference, 612-631, 2018.

[30] S. Stirenko, Y. Gordienko, T. Shemsedinov, O. Alienin, Y. Kochura, N. Gordienko, A. Rojbi, J. Benito, E. A. González, "User-driven intelligent interface on the basis of multimodal augmented reality and brain-computer interaction for people with functional disabilities", arXiv preprint arXiv:1704.05915, 2017.

[31] A. Pereira, E. J. Carter, I. Leite, J. Mars, J. F. Lehman, "Augmented reality dialog interface for multimodal teleoperation", 26th IEEE International Symposium on Robot and Human Interactive Communication (RO-MAN), 764-771, 2017.

[32] A. Karambakhsh, A. Kamel, B. Sheng, P. Li, P. Yang, D. D. Feng, "Deep gesture interaction for augmented anatomy learning", International Journal of Information Management, 45(1), 328-336, 2019.

[33] Z. Taçgın, Ameliyathanede kullanılan cerrahi setlerin öğretimine yönelik bir sanal gerçeklik simülasyonunun geliştirilmesi ve değerlendirilmesi, $\mathrm{PhD}$ Thesis, Marmara University, Educational Science Institute, 2017. 